\title{
Incidence and risk of hypertension with bevacizumab in non-small-cell lung cancer patients: a meta-analysis of randomized controlled trials
}

\author{
This article was published in the following Dove Press journal: \\ Drug Design, Development and Therapy \\ 18 August 2015 \\ Number of times this article has been viewed
}

\author{
Jian Chen' \\ Yingfeng $\mathrm{Lu}^{2}$ \\ Yunliang Zheng ${ }^{3}$ \\ 'Intensive Care Unit, First Affiliated \\ Hospital, College of Medicine, \\ Zhejiang University, ${ }^{2}$ State Key \\ Laboratory for Diagnosis and \\ Treatment of Infectious Diseases, \\ First Affiliated Hospital, College \\ of Medicine, Zhejiang University, \\ ${ }^{3}$ Research Center for Clinical \\ Pharmacy, State Key Laboratory for \\ Diagnosis and Treatment of Infectious \\ Diseases, First Affiliated Hospital, \\ Zhejiang University, Hangzhou, \\ People's Republic of China
}

Correspondence: Yunliang Zheng Research Center for Clinical Pharmacy, State Key Laboratory for Diagnosis and Treatment of Infectious Diseases, First Affiliated Hospital, Zhejiang University, 79 Qing Chun Road, Hangzhou, Zhejiang 310003,

People's Republic of China

Tel/fax +86 57/ 87236537

Email ylzheng1984@zju.edu.cn

\begin{abstract}
Aim: A study was conducted to determine the overall risk and incidence of hypertension with bevacizumab in non-small-cell lung cancer (NSCLC) patients.

Materials and methods: Electronic databases such as the Embase, PubMed, and Cochrane Library were searched for related trials. Statistical analyses were conducted to calculate the overall incidence rates, odds ratios (ORs), and 95\% confidence intervals (CIs) by using either random-effect or fixed-effect models depending on the heterogeneity.

Results: A total of 3,155 subjects from nine studies were included. The overall incidences of all-grade and high-grade hypertension in NSCLC patients were $19.55 \%$ (95\% CI 10.17\%-34.3\%) and $6.95 \%$ (95\% CI 5.81\%-8.30\%). Bevacizumab use was associated with a significantly increased risk in all-grade hypertension (OR 8.07, 95\% CI 3.87-16.85; $P=0.0002$ ) and highgrade hypertension (OR 5.93, 95\% CI 3.41-10.32; $P<0.0001$ ). No evidence of publication bias was determined for the ORs of hypertension in our meta-analysis.

Conclusion: Bevacizumab is associated with a significantly increased risk of hypertension development in NSCLC patients. Early monitoring and effective management of hypertension might be important steps for the safe use of this drug.
\end{abstract}

Keywords: non-small-cell lung cancer, bevacizumab, hypertension, meta-analysis

\section{Introduction}

Lung cancer is the leading cause of cancer-related mortality in the world, and non-small-cell lung cancer (NSCLC) is the diagnosis in approximately $85 \%$ of lung cancer patients. ${ }^{1}$ Platinum-based doublet chemotherapy is the first-line treatment option for NSCLC ${ }^{2}$ however, only $35 \%$ of the patients respond to standard treatment. ${ }^{3}$ Targeted therapies, such as the vascular endothelial growth factor receptor (VEGFR) inhibitors or other monoclonal antibodies, have been clinically validated to improve the outcome of NSCLC patients. ${ }^{4,5}$ vascular endothelial growth factor (VEGF) can activate VEGFR and downstream signaling molecules, thereby promoting tumor angiogenesis. Bevacizumab is a novel orally recombinant humanized monoclonal anticancer agent that inhibits the VEGF pathway, which is a crucial growth driver for tumor growth, invasion, and metastasis. ${ }^{6}$ The clinical benefits of bevacizumab administration in NSCLC patients have been observed in several trials..$^{5,7}$ In a previous Phase III trial, bevacizumab reduced the risk of disease progression by $50 \%$ in NSCLC patients compared with controls. ${ }^{9}$ In a previous meta-analysis, the inclusion of bevacizumab to platinum-based chemotherapy significantly extended progression-free survival and overall survival. ${ }^{10}$ 
Bevacizumab can effectively treat NSCLC, but using this drug can lead to significant toxic reactions, such as diarrhea, nausea, hemorrhage, fatigue, neuropathy, joint pain, venous thromboembolism, and hematologic toxicity. $8,11,12$ NSCLC patients treated with bevacizumab may also develop hypertension. A Phase II study of Japanese patients who received first-line carboplatin-paclitaxel (CP) with or without bevacizumab showed that 57 of 119 patients who received bevacizumab had developed all-grade hypertension compared with six of 58 patients in the control group. Grade $\geq 3$ hypertension was not reported in any patients treated with $\mathrm{CP}$ alone, but the condition occurred in $11 \%$ of the patients treated with bevacizumab-CP. ${ }^{11}$ However, because of the limited number of hypertension events in each clinical trial, the overall incidence and risk of hypertension caused by bevacizumab has not been well defined. A study on the occurrence of hypertension in patients receiving bevacizumab treatment may offer additional insights into the underlying mechanisms, risk factors, and potential management strategies. Moreover, hypertension events should be monitored because poor management may lead to serious cardiovascular events, dose reduction, or even life-threatening consequences. Therefore, we conducted this meta-analysis to investigate hypertension incidence and relative risk among bevacizumab-treated NSCLC patients.

\section{Materials and methods Search strategy and study selection}

Because this study was based on data extracted from registries, it was exempt from human subjects review, and members of the study population did not have to provide informed consent. We searched electronic databases for literature published up to April 2015; these databases were Embase (from 1974), PubMed (from 1967), and the Cochrane Library. The search terms, used as free text or MeSH (Medical Subject Headings) terms for the queries, were: "non-small-cell lung cancer" and "carcinoma, non-small-cell lung"; "bevacizumab"; and "randomized controlled trials", "clinical trials", "controlled clinical trials", "clinical trial as topic", or "randomized controlled trial as topic". In addition, we searched for relevant randomized controlled trials (RCTs) among the meeting abstracts and virtual presentations of the American Society of Clinical Oncology (http://www.asco. org/ASCO) published up to 2015. Additionally, we searched a clinical trial-registration website (ClinicalTrials.gov) to obtain information on registered clinical trials.

Study selection was conducted according to the Preferred Reporting Items for Systematic Reviews and Meta-Analyses
(PRISMA) statement. Clinical trials that met the following criteria included: 1) patients with NSCLC, 2) prospective Phase II or III RCTs that compared bevacizumab with controls, and 3) available data regarding events of hypertension. Data on hypertension were extracted from the safety profile of each RCT. These clinical end points were obtained according to the Common Terminology Criteria for Adverse Events (CTCAE) of the National Cancer Institute (http:// ctep.cancer.gov/reporting/ctc archive.html).

\section{Data extraction and quality assessment}

Independently, two investigators (Yunliang Zheng and Jian Chen) extracted data from the included trials, and the respective studies were retrieved for further consideration if judged pertinent by one or two reviewers. Any discrepancies were identified and resolved by consensus. For each trial, the following data were extracted: first author's name, year of publication, treatment arm, media progression-free survival, media overall survival, number of patients in the bevacizumab and control groups, and adverse outcomes (allgrade hypertension and high-grade hypertension). The Jadad criteria were used to assess the quality of all included RCTs in this review. ${ }^{13}$ Scores ranged from 0 to 5 , with a high score indicating a high-quality study.

\section{Data analysis}

The principal summary measures were the incidence, odds ratio (OR), and corresponding 95\% confidence interval (CI). For the calculation of incidence, the number of patients with all grades and high grades (grades 3 and 4) of hypertension, as well as the number of patients receiving bevacizumab, were obtained. The proportion of patients with hypertension and the $95 \%$ CI was derived for each study. The OR of hypertension was only calculated for studies that assigned a control group in the same trial. $P$-values less than 0.05 were considered significant. The Peto method was used to calculate the OR and the $95 \%$ CI, because this method provided the best $\mathrm{CI}$ coverage; this method was more powerful and relatively less biased in addressing low event rates. ${ }^{14}$ Heterogeneity was assessed by the $Q$-statistic and $I^{2}$ tests among clinical trials. ${ }^{15,16}$ Heterogeneity was considered statistically significant when $P<0.1$ or $I^{2}>40 \%$. If heterogeneity was present, the data were analyzed by a random-effect model; otherwise, a fixed-effect model was used. The presence of publication bias was evaluated by funnel plots, Begg's test, and Egger's test. ${ }^{17,18}$ All data analyses were performed with $R$ software, version 3.0.3 ( $R$ Foundation for Statistical Computing [http:// www.r-project.org]). 


\section{Results}

\section{Search results and trial characteristics}

A total of 1,776 studies were retrieved from an initial search. After reviewing each study, 1,767 studies were excluded. Figure 1 outlines the details of the selection process. The remaining nine studies ${ }^{8,9,11,12,19-23}$ had a total of 3,155 subjects that met our inclusion criteria, and were included in our analyses. The age of all subjects was over 18 years. The number of female subjects was 769 in the bevacizumabtreatment group, and the number of female subject was 527 in the control group. The characteristics of each trial are summarized in Table 1 . The quality of the nine clinical trials was high: two studies had Jadad scores of 5, 9,12 which provided the number of patients who withdrew and dropped from the trials, as well as described the methods of randomization and blinding. Two studies had Jadad scores of $4,8,11$ which were attributed to the fact that the investigators did not appropriately describe the methods of blinding or randomization. Five studies had Jadad scores of 3. ${ }^{19-23}$ Meta-analysis was performed by following the guidelines of the PRISMA statement (Table S1).

\section{Incidence of all-grade and high-grade hypertension}

A total of 402 patients from six studies ${ }^{8,11,20-23}$ were treated with bevacizumab, and the incidence of all-grade hypertension was analyzed. The incidence of all-grade hypertension ranged from $5.36 \%$ to $47.9 \%$. The highest incidence occurred

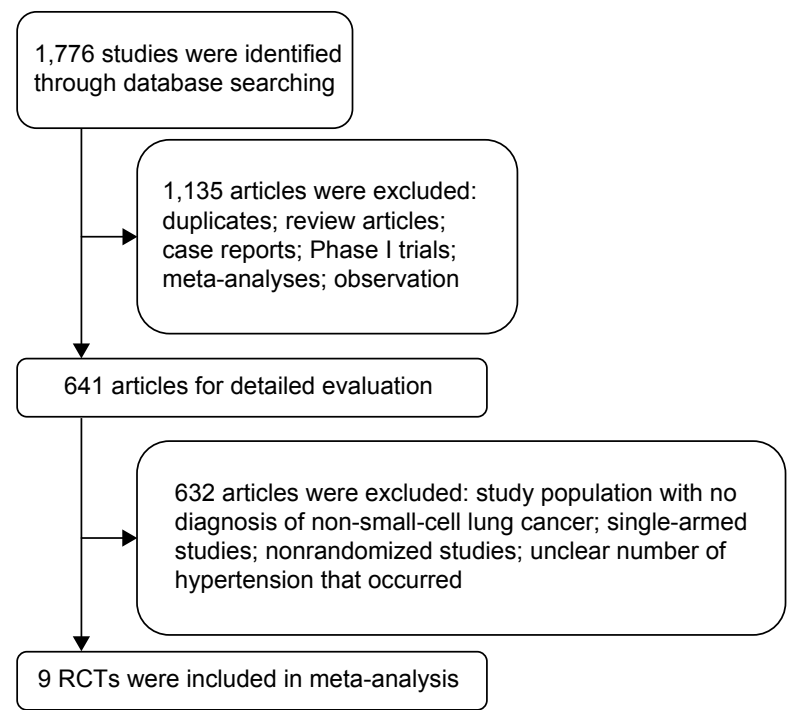

Figure I Flowchart demonstrating the study-selection process. Abbreviation: RCTs, randomized controlled trials.

in a Phase II trial of Japanese patients with advanced nonsquamous NSCLC. ${ }^{11}$ The lowest incidence was recorded in a Phase III trial. ${ }^{23}$ Based on data from included trials, the calculated overall incidence of all-grade hypertension was $19.55 \%$ (95\% CI 10.17\%-34.3\%; Figure 2) according to the random-effects model $\left(I^{2}=88.3 \%, P<0.001\right)$.

High-grade (grade 3 or 4 ) hypertension had serious adverse reactions that might have been associated with distinct morbidity and could result in the discontinuation of bevacizumab treatment. A total of 1,680 patients from

Table I Baseline characteristics of trials included in the meta-analysis $(n=3,155)$

\begin{tabular}{|c|c|c|c|c|c|c|c|c|c|}
\hline \multirow[t]{2}{*}{ Study } & \multirow[t]{2}{*}{ Year } & \multirow{2}{*}{$\begin{array}{l}\text { Trial } \\
\text { phase }\end{array}$} & \multirow{2}{*}{$\begin{array}{l}\text { Treatment } \\
\text { arms }\end{array}$} & \multirow{2}{*}{$\begin{array}{l}\text { Median PFS } \\
\text { (months) }\end{array}$} & \multirow{2}{*}{$\begin{array}{l}\text { Median OS } \\
\text { (months) }\end{array}$} & \multicolumn{2}{|l|}{ HEs, $n$} & \multirow{2}{*}{$\begin{array}{l}\text { Enrolled } \\
\text { patients, n }\end{array}$} & \multirow{2}{*}{$\begin{array}{l}\text { Jadad } \\
\text { score }\end{array}$} \\
\hline & & & & & & All grade & High grade & & \\
\hline \multirow[t]{2}{*}{ Johnson et $\mathrm{al}^{8}$} & 2004 & 2 & Beva + PC & 7 & 17.7 & 11 & 2 & 67 & 4 \\
\hline & & & PC & 5.9 & 14.9 & I & 1 & 32 & \\
\hline \multirow[t]{2}{*}{ Sandler et al ${ }^{19}$} & 2006 & 3 & Beva + PC & 6.2 & 12.3 & NR & 30 & 427 & 3 \\
\hline & & & PC & 4.5 & 10.3 & NR & 3 & 440 & \\
\hline \multirow[t]{2}{*}{ Herbst et $\mathrm{al}^{20}$} & 2007 & 2 & Beva + DP & 4.8 & 12.6 & 6 & 2 & 39 & 3 \\
\hline & & & DP & 3 & 8.6 & 0 & 0 & 42 & \\
\hline \multirow[t]{2}{*}{ Reck et $\mathrm{al}^{12}$} & 2009 & 3 & Beva + CG & 6.5 & 13.4 & NR & 49 & 659 & 5 \\
\hline & & & Placebo + CG & 6.1 & 13.1 & NR & 5 & 327 & \\
\hline \multirow[t]{2}{*}{ Herbst et $\mathrm{al}^{9}$} & 2011 & 3 & Beva + Erl & 3.4 & 9.3 & NR & 15 & 313 & 5 \\
\hline & & & Placcbo + Erl & 1.7 & 9.2 & NR & 4 & 313 & \\
\hline \multirow[t]{2}{*}{ Soria et $\mathrm{al}^{21}$} & 2011 & 2 & PC + Dulanermin & 5.5 & 9.8 & NR & NR & 39 & 3 \\
\hline & & & Beva + Dulanermin & 8.6 & 13.9 & 22 & NR & 81 & \\
\hline \multirow[t]{2}{*}{ Niho et al' } & 2012 & 2 & $\mathrm{PC}$ & 6.9 & 22.8 & 6 & 0 & 58 & 4 \\
\hline & & & Beva + PC & 5.9 & 23.4 & 57 & 13 & 119 & \\
\hline \multirow[t]{2}{*}{ Spigel et $\mathrm{al}^{22}$} & 2012 & 2 & Beva + IC & 6.7 & 13.2 & 6 & NR & 40 & 3 \\
\hline & & & IC & 5.3 & 9.3 & I & NR & 42 & \\
\hline \multirow[t]{2}{*}{ Boutsikou et $\mathrm{al}^{23}$} & 2013 & 3 & Beva + DC & NR & 19.1 & 3 & 2 & 56 & 3 \\
\hline & & & $\mathrm{DC}$ & NR & 15.3 & 0 & 0 & 61 & \\
\hline
\end{tabular}

Abbreviations: PFS, progression-free survival; OS, overall survival; HEs, hypertension events; Beva, bevacizumab; PC, paclitaxel + carboplatin; DP, docetaxel or pemetrexed; CG, cisplatin + gemcitabine; Erl, erlotinib; IC, ixabepilone + carboplatin; DC, docetaxel + carboplatin; NR, not reported. 


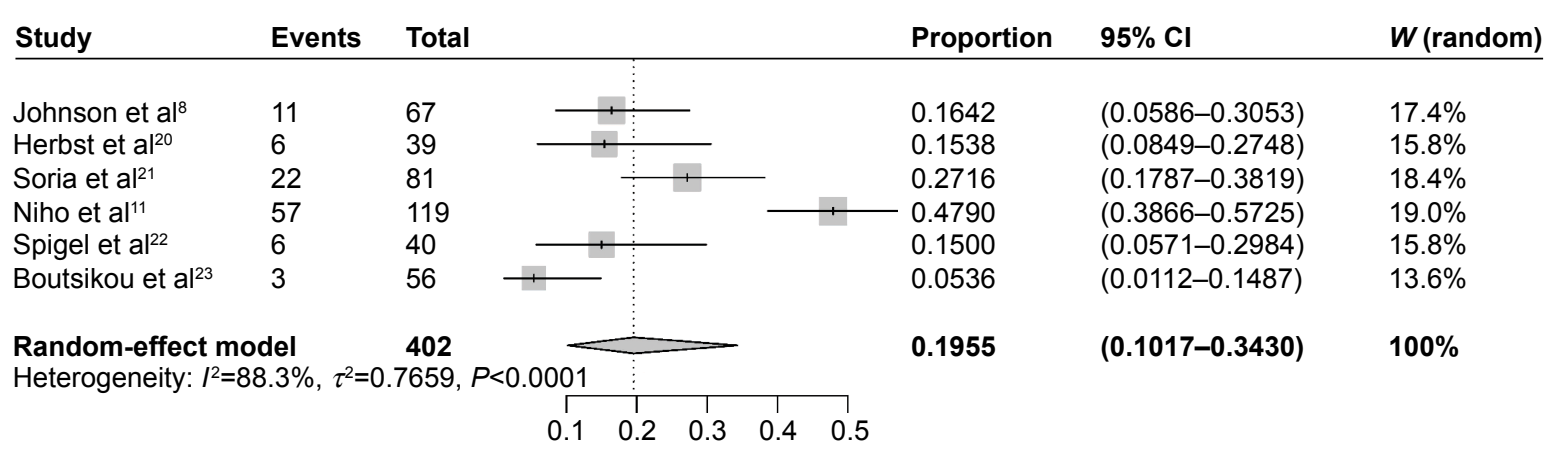

Figure 2 Forest plot for the meta-analysis of the incidence of all-grade hypertension with bevacizumab-treated patients.

Abbreviation: $\mathrm{Cl}$, confidence interval.

seven trials were available for the incidence of highgrade hypertension analysis. ${ }^{8,9,11,12,19,20,23}$ The incidence of high-grade hypertension ranged from $2.99 \%$ to $10.92 \%$. The highest incidence occurred in the Phase II trial of Japanese patients with advanced nonsquamous NSCLC. ${ }^{11}$ The lowest incidence occurred in patients with advanced or metastatic NSCLC. ${ }^{8}$ The overall incidence of highgrade hypertension was $6.95 \%$ (95\% CI 5.81\%-8.30\%; Figure 3$)$ according to the fixed-effect model $\left(I^{2}=24.9 \%\right.$, $P=0.2392)$.

\section{Relative risk of all-grade hypertension}

The specific contribution of bevacizumab to the development of hypertension in patients was determined by excluding the influence of confounding factors, such as history of other therapeutic interventions. We calculated the OR of all-grade hypertension between the bevacizumab and control groups. The pooled OR for all-grade hypertension cases indicated that bevacizumab treatment significantly increased the risk of developing all-grade hypertension in NSCLC patients, with an OR of 8.07 (95\% CI 3.87-16.85, $P=0.0002$; Figure 4) according to the fixed-effect model $\left(I^{2}=0, P=0.9891\right) .^{8,11,20,22,23}$

\section{Relative risk of high-grade hypertension}

High-grade (grade 3 or 4) hypertension is an important index of bevacizumab safety. Our meta-analysis of the OR for high-grade hypertension attributable to bevacizumab in comparison with the controls was performed on seven RCTs with a total of 2,953 patients. The pooled OR for high-grade hypertension demonstrated that treatment with bevacizumab significantly increased the risk of developing high-grade hypertension in NSCLC patients, with an OR of 5.93 (95\% CI 3.41-10.32, $P<0.0001$; Figure 5) according to the fixedeffect model $\left.\left(I^{2}=0 \%, P=0.6465\right)\right)^{8,9,11,12,19,20,23}$

\section{Publication bias}

No evidence of publication bias was found for the OR of hypertension in our meta-analysis by funnel plot (Figure 6), Egger's test ( $95 \% \mathrm{CI}-2.05$ to $1.78, P=0.862$ ), or Begg's test $(Z=0.3, Z<1.96 ; P=0.76)$.

\section{Discussion}

Bevacizumab has been clinically validated as a targeted agent against in NSCLC by inhibiting the signaling pathways of VEGF. ${ }^{9,12}$ Unlike traditional chemotherapy agents, ${ }^{24-26}$ bevacizumab has advanced efficacy and

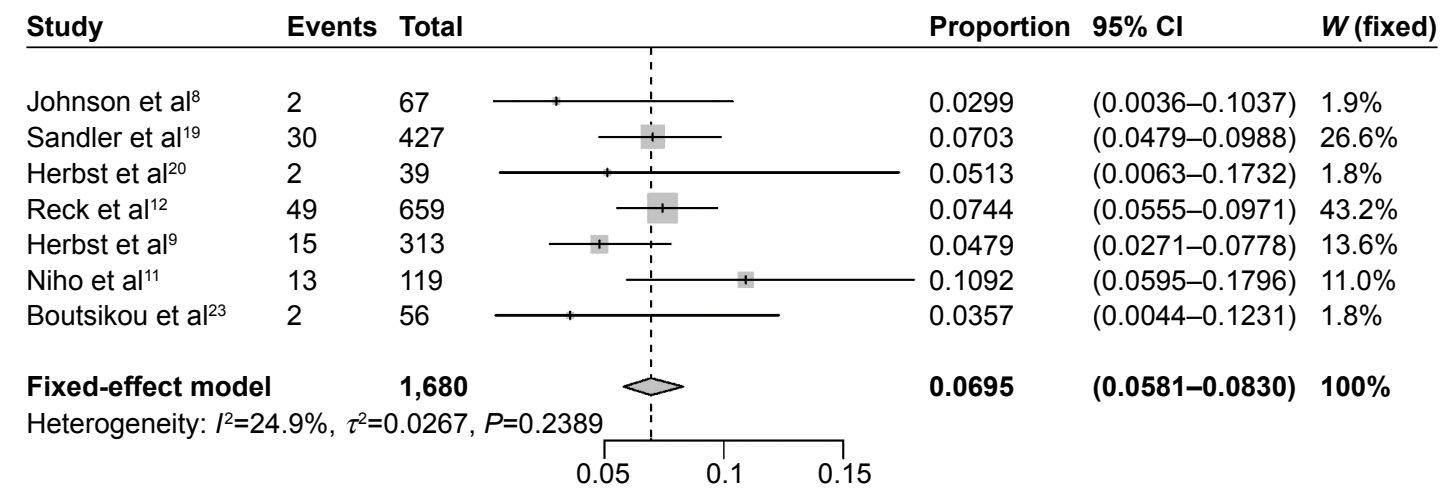

Figure 3 Forest plot for meta-analysis of the incidence of high-grade hypertension with bevacizumab-treated patients. Abbreviation: $\mathrm{Cl}$, confidence interval. 


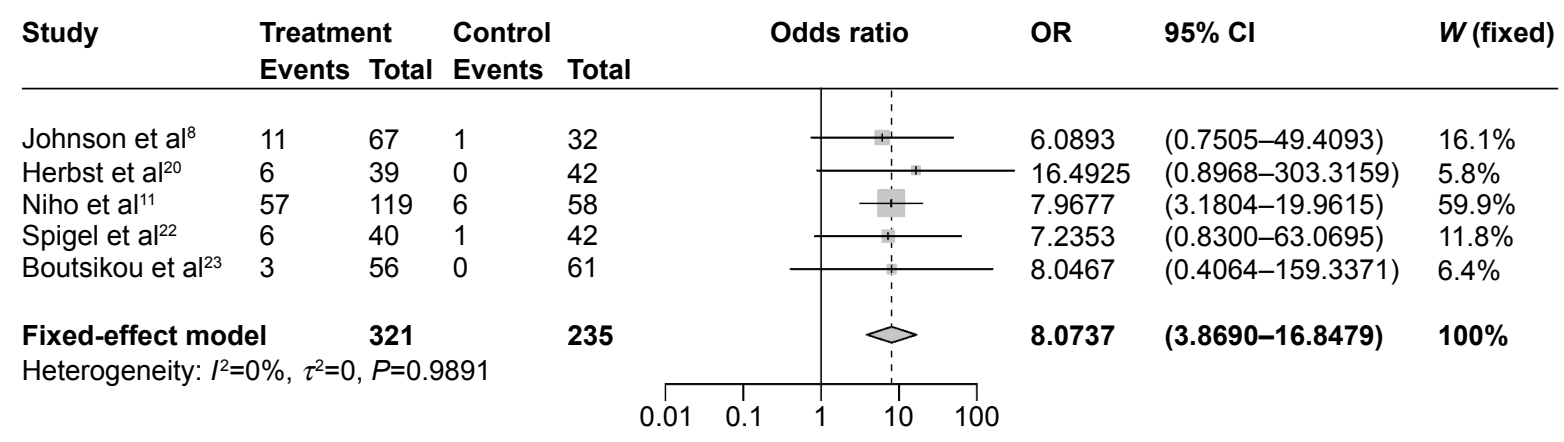

Figure 4 Relative risk of bevacizumab-associated all-grade hypertension.

Abbreviations: $\mathrm{OR}$, odds ratio; $\mathrm{Cl}$, confidence interval.

lower toxicity. However, adverse effects in patients with bevacizumab treatment include hypertension, nausea, hemorrhage, fatigue, and neuropathy. ${ }^{27,28}$ Hypertension is commonly associated with bevacizumab in clinical trials. This condition may lead to serious cardiovascular events or even life-threatening consequences. The incidence and management for hypertension is important in NSCLC patients with bevacizumab treatment. However, the overall incidence and risk of bevacizumab-induced hypertension remains unknown. The present meta-analysis was performed to calculate its overall incidence and to compare differences in incidence rates between bevacizumab treatment and controls.

Meta-analysis is a formidable statistical tool that can be used to assess the incidence and risk factors of drug-related adverse reactions. Meta-analysis results can increase the number of clinical samples and improve productivity based on statistical evidence. In addition, meta-analysis reaches more valid conclusions for the selection of suitable therapeutic schemes in clinical practice. To the best of our knowledge, we are the first to estimate the incidence and risk of hypertension associated with bevacizumab treatment in patients with NSCLC.
Our meta-analysis included a total of 3,155 subjects from nine studies, and we demonstrated that the overall incidence rate of all-grade hypertension was $19.55 \%$, whereas the incidence rate of high-grade hypertension was $6.79 \%$. There are also several factors that should be considered in the rate reported in our study, such as the size of each selected study and patient features (sex, age, etc). Additionally, the use of bevacizumab is associated with significantly increased incidence of all-grade and high-grade hypertension compared with controls. The OR of all-grade hypertension was 8.07, and that of high-grade hypertension was 5.93. According to a report by Hong et al, ${ }^{29}$ the relative risk of all-grade hypertension in advanced NSCLC patients treated with angiogenesis inhibitors was 3.23 (95\% CI 1.93-5.41, $P<0.001)$, and the relative risk of high-grade hypertension in advanced NSCLC patients treated with angiogenesis inhibitors was 5.42 (95\% CI 4.06-7.22, $P<0.001)$. Our results were similar to Hong et al. Based on our results, we concluded that bevacizumab treatment was associated with an unexpectedly high risk of developing hypertension. Continuous monitoring and effective hypertension management are important during bevacizumab treatment.

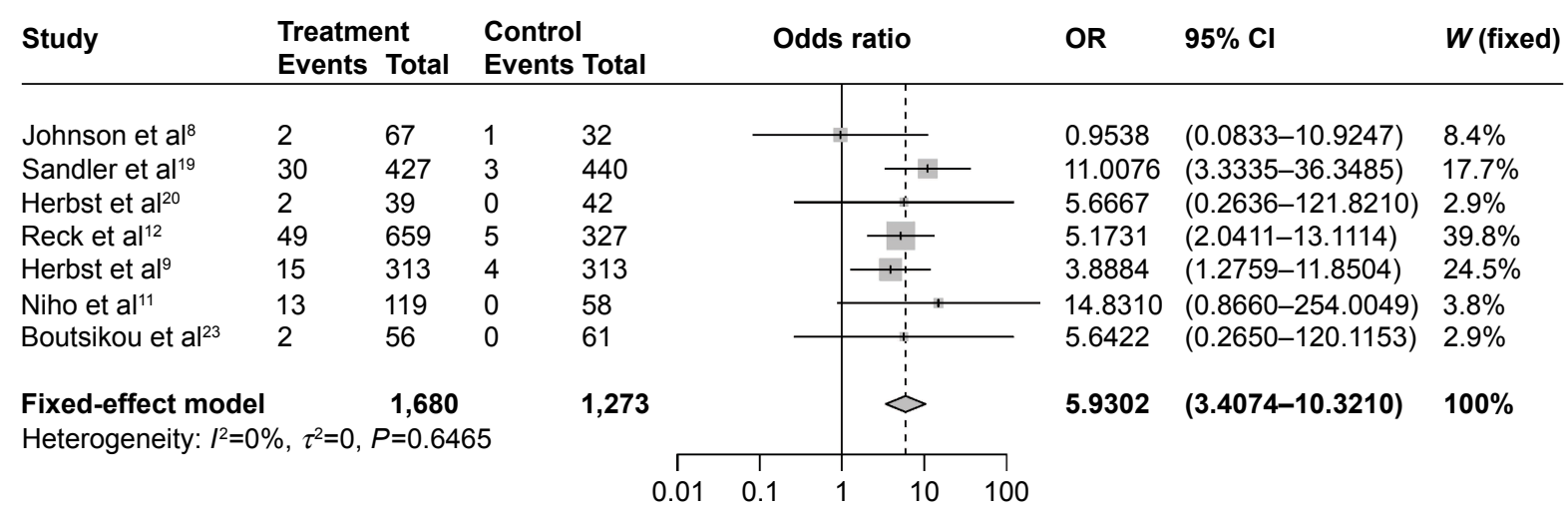

Figure 5 Relative risk of bevacizumab-associated high-grade hypertension. Abbreviations: $\mathrm{OR}$, odds ratio; $\mathrm{Cl}$, confidence interval. 


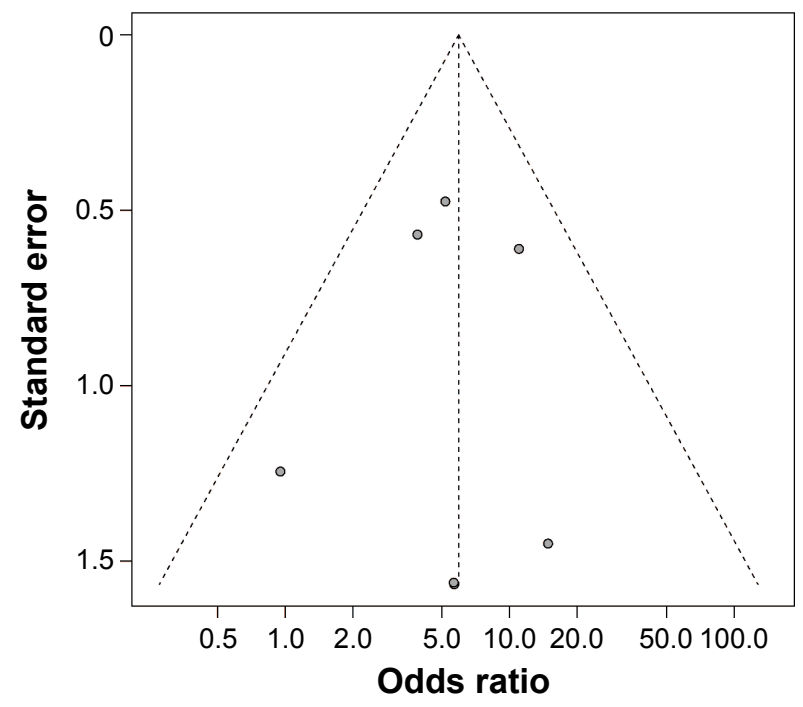

Figure 6 Funnel-plot standard error based on the odds ratio for relative risk of high-grade hypertension.

Bevacizumab is used to treat a more heterogeneous patient population than those found in clinical trials. More effort is required to limit the risk of hypertension. Bevacizumab-administered patients need to be carefully monitored for hypertension symptoms, especially if these patients have cardiovascular disease or other risk factors. ${ }^{30}$ Furthermore, the use of bevacizumab can cause high-grade hypertension, as described by the CTCAE of the National Cancer Institute. Therefore, patients treated with this drug should be monitored for symptoms, such as fever, dyspnea, and hypoxemia, during bevacizumab administration. Clinicians should be aware of the possibility that any patient treated with bevacizumab may develop hypertension, especially those at high risk. In addition to its anti-NSCLC properties, bevacizumab is used against other tumor types, particularly colon cancer. ${ }^{31,32}$ The incidence of hypertension in other cancer patients should be considered.

The mechanism of bevacizumab-associated hypertension has not been clarified, and may be associated with the suppression of nitric oxide production in endothelial cells. ${ }^{33}$ Whether via pharmacological or genetic methods, the inhibition of the VEGF pathway in endothelial cells can induce thrombotic microangiopathy, endotheliosis, and narrow capillaries in patients treated with VEGF-targeting agents. ${ }^{34}$ The relationship between hypertension and the patient's response to bevacizumab may be related to gene polymorphism. Previous studies have determined that genetic variants of the VEGFR and vascular endothelial growth factor A (VEGFA) are associated with the patient's reaction to bevacizumab treatment. ${ }^{35,36}$ These genetic variants could increase the response of endothelial cells to anti-VEGF-targeted agents, which may be directed at the increased risk of cardiac toxicity. Therefore, patients developing hypertension during bevacizumab therapy may be influenced by these variants. Hypertension associated with polymorphisms of VEGF has been reported in patients treated with sunitinib and bevacizumab. ${ }^{37}$

Although bevacizumab-associated hypertension is an important side effect reported in clinical trials, the management of this side effect is controversial. Guidelines of the American Heart Association ${ }^{38}$ and the European Society of Hypertension $^{39}$ do not mention measures against induced hypertension. Furthermore, no evidence-based suggestions are available. Therefore, clinicians are free to choose the best therapeutic strategy for their patients. A large number of clinical trials have shown that the main effects of antihypertensive treatment are largely independent of the drugs used. In addition, $\beta$-adrenoceptor antagonists, angiotensin converting enzyme (ACE) inhibitors, angiotensin-receptor antagonists, and calcium antagonists can adequately lower blood pressure and markedly decrease the frequency of cardiovascular events. ${ }^{40,41}$ Therefore, all the aforementioned agents can be used as antihypertensive treatment either in alone or in combination. Of course, it should be noted that because VEGF inhibitors interact with cytochrome enzymes, the metabolism of some antihypertensive drugs, such as calcium-channel blockers, is affected, and hence, these antihypertensive drugs may not be effective in patients treated with VEGF inhibitors. According to the British Columbia Cancer Agency recommendations for the management of adverse effects of bevacizumab, a thiazine diuretic should be the first-line treatment and angiotensin-receptor blockers or ACE inhibitors can be the second-line treatment. However, diuretic treatment of patients under concurrent chemotherapy should be performed with caution to prevent volume depletion. ${ }^{42}$

Our meta-analysis has several limitations. First, we may have underestimated the incidence of bevacizumab-associated hypertension because of the definition of the CTCAE. Under the CTCAE, patients are considered hypertensive only if the blood pressure is greater than $150 / 100 \mathrm{mmHg}$ or the diastolic pressure is increased by more than $20 \mathrm{mmHg}$. In our study, this strict criteria would have reduced the number of hypertensive patients compared with the real-world criteria for the diagnosis of hypertension $(140 / 90 \mathrm{mmHg})$. Second, RCTs have strict inclusion and exclusion criteria. Only patients with adequate major organ function are included in these trials; therefore, the results of our meta-analysis may not represent actual patients. ${ }^{43,44}$ Our results may not 
be applicable to the general population in daily practice. Third, hypertension events are collected for each individual trial, but potentially differences among the trials may exist, as follows: various international institutions, administration schedules of bevacizumab, and periods of study. All of these differences would increase the clinical heterogeneity among the included trials, ${ }^{45}$ which contributed to the difficulty of interpreting the results of our analysis. Finally, the treatment designs varied, and the analysis did not focus on individual patient data. Meta-analyses that are based on published data tend to overestimate the treatment effects compared with individual patient data analyses. ${ }^{46}$

\section{Conclusion}

Our study suggested that bevacizumab treatment in NSCLC patients is associated with a significantly increased risk of developing hypertension. Early monitoring and effective management of hypertension could be an important step for the safer use of this drug. Further studies should be conducted to identify the mechanism of bevacizumab-associated hypertension.

\section{Disclosure}

The authors report no conflicts of interest in this work.

\section{References}

1. Siegel R, Ma J, Zou Z, Jemal A. Cancer statistics, 2014. CA Cancer J Clin. 2014;64(1):9-29.

2. NSCLC Meta-Analyses Collaborative Group. Chemotherapy in addition to supportive care improves survival in advanced non-small-cell lung cancer: a systematic review and meta-analysis of individual patient data from 16 randomized controlled trials. J Clin Oncol. 2008;26(28):4617-4625.

3. Stinchcombe TE, Socinski MA. Current treatments for advanced stage non-small cell lung cancer. Proc Am Thorac Soc. 2009;6(2):233-241.

4. Francis H, Solomon B. The current status of targeted therapy for nonsmall cell lung cancer. Intern Med J. 2010;40(9):611-618.

5. Parums DV. Current status of targeted therapy in non-small cell lung cancer. Drugs Today (Barc). 2014;50(7):503-525.

6. Zetter BR. Angiogenesis and tumor metastasis. Annu Rev Med. 1998; 49:407-424.

7. Chiappori AA, Kolevska T, Spigel DR, et al. A randomized phase II study of the telomerase inhibitor imetelstat as maintenance therapy for advanced non-small-cell lung cancer. Ann Oncol. 2015;26(2):354-362.

8. Johnson DH, Fehrenbacher L, Novotny WF, et al. Randomized phase II trial comparing bevacizumab plus carboplatin and paclitaxel with carboplatin and paclitaxel alone in previously untreated locally advanced or metastatic non-small-cell lung cancer. J Clin Oncol. 2004; 22(11):2184-2191.

9. Herbst RS, Ansari R, Bustin F, et al. Efficacy of bevacizumab plus erlotinib versus erlotinib alone in advanced non-small-cell lung cancer after failure of standard first-line chemotherapy (BeTa): a doubleblind, placebo-controlled, phase 3 trial. Lancet. 2011;377(9780): 1846-1854.

10. Su Y, Yang WB, Li S, Ye ZJ, Shi HZ, Zhou Q. Effect of angiogenesis inhibitor bevacizumab on survival in patients with cancer: a metaanalysis of the published literature. PloS One. 2012;7(4):e35629.
11. Niho S, Kunitoh H, Nokihara H, et al. Randomized phase II study of first-line carboplatin-paclitaxel with or without bevacizumab in Japanese patients with advanced non-squamous non-small-cell lung cancer. Lung Cancer. 2012;76(3):362-367.

12. Reck M, von Pawel J, Zatloukal P, et al. Phase III trial of cisplatin plus gemcitabine with either placebo or bevacizumab as first-line therapy for nonsquamous non-small-cell lung cancer: AVAil. J Clin Oncol. 2009;27(8):1227-1234.

13. Jadad AR, Moore RA, Carroll D, et al. Assessing the quality of reports of randomized clinical trials: is blinding necessary? Control Clin Trials. 1996;17(1):1-12.

14. Sweeting MJ, Sutton AJ, Lambert PC. What to add to nothing? Use and avoidance of continuity corrections in meta-analysis of sparse data. Stat Med. 2004;23(9):1351-1375.

15. Zintzaras E, Ioannidis JP. Heterogeneity testing in meta-analysis of genome searches. Genet Epidemiol. 2005;28(2):123-137.

16. Higgins JP, Thompson SG, Deeks JJ, Altman DG. Measuring inconsistency in meta-analyses. BMJ. 2003;327(7414):557-560.

17. Begg CB, Mazumdar M. Operating characteristics of a rank correlation test for publication bias. Biometrics. 1994;50(4):1088-1101.

18. Egger M, Davey Smith G, Schneider M, Minder C. Bias in meta-analysis detected by a simple, graphical test. BMJ. 1997;315(7109):629-634.

19. Sandler A, Gray R, Perry MC, et al. Paclitaxel-carboplatin alone or with bevacizumab for non-small-cell lung cancer. $N$ Engl J Med. 2006;355(24):2542-2550.

20. Herbst RS, O’Neill VJ, Fehrenbacher L, et al. Phase II study of efficacy and safety of bevacizumab in combination with chemotherapy or erlotinib compared with chemotherapy alone for treatment of recurrent or refractory non small-cell lung cancer. J Clin Oncol. 2007;25(30):4743-4750.

21. Soria JC, Márk Z, Zatloukal P, et al. Randomized phase II study of dulanermin in combination with paclitaxel, carboplatin, and bevacizumab in advanced non-small-cell lung cancer. J Clin Oncol. 2011;29(33): 4442-4451.

22. Spigel DR, Greco FA, Waterhouse DM, et al. Phase II trial of ixabepilone and carboplatin with or without bevacizumab in patients with previously untreated advanced non-small-cell lung cancer. Lung Cancer. 2012;78(1):70-75.

23. Boutsikou E, Kontakiotis T, Zarogoulidis P, et al. Docetaxel-carboplatin in combination with erlotinib and/or bevacizumab in patients with nonsmall cell lung cancer. Onco Targets Ther. 2013;6:125-134.

24. Artal Cortés A, Calera Urquizu L, Hernando Cubero J. Adjuvant chemotherapy in non-small cell lung cancer: state-of-the-art. Transl Lung Cancer Res. 2015;4(2):191-197.

25. Petrioli R, Francini E, Fiaschi AI, et al. Switch maintenance treatment with oral vinorelbine and bevacizumab after induction chemotherapy with cisplatin, gemcitabine and bevacizumab in patients with advanced non-squamous non-small cell lung cancer: a phase II study. Med Oncol. 2015;32(4):134.

26. Tamiya A, Tamiya M, Shiroyama T, et al. Phase II trial of carboplatin, $\mathrm{S}-1$, and gefitinib as first-line triplet chemotherapy for advanced nonsmall cell lung cancer patients with activating epidermal growth factor receptor mutations. Med Oncol. 2015;32(3):40.

27. Montero JA, Yanez-Castro G, Sanchis-Merino ME, Ruiz-Moreno JM. Bevacizumab in vitreous haemorrhage secondary to radiation retinopathy. BMJ Case Rep. 2014;2014.

28. Fu DB, Alexandru D, Curticiu DM, Fu Y, Bota DA. Two patients with brain tumors who received bevacizumab and radiotherapy: optic neuropathy and quality-of-life issues. J Adv Pract Oncol. 2013;4(4): 252-256.

29. Hong S, Tan M, Wang S, Luo S, Chen Y, Zhang L. Efficacy and safety of angiogenesis inhibitors in advanced non-small cell lung cancer: a systematic review and meta-analysis. J Cancer Res Clin Oncol. 2015;141(5): 909-921.

30. Pereg D, Lishner M. Bevacizumab treatment for cancer patients with cardiovascular disease: a double edged sword? Eur Heart J. 2008;29(19) 2325-2326. 
31. Kaidar-Person O, Badarna H, Bar-Sela G. Bevacizumab for metastatic colon cancer: does patient BMI influence survival? Anticancer Drugs. 2015;26(3):363-366.

32. Hamdollah Zadeh MA, Amin EM, Hoareau-Aveilla C, et al. Alternative splicing of TIA-1 in human colon cancer regulates VEGF isoform expression, angiogenesis, tumour growth and bevacizumab resistance. Mol Oncol. 2015;9(1):167-178.

33. Robinson ES, Khankin EV, Choueiri TK, et al. Suppression of the nitric oxide pathway in metastatic renal cell carcinoma patients receiving vascular endothelial growth factor-signaling inhibitors. Hypertension. 2010;56(6):1131-1136.

34. Eremina V, Sood M, Haigh J, et al. Glomerular-specific alterations of VEGF-A expression lead to distinct congenital and acquired renal diseases. J Clin Invest. 2003;111(5):707-716.

35. Lambrechts D, Claes B, Delmar P, et al. VEGF pathway genetic variants as biomarkers of treatment outcome with bevacizumab: an analysis of data from the AViTA and AVOREN randomised trials. Lancet Oncol. 2012;13(7):724-733.

36. Yu J, Cao XF, Zheng Y, et al. Anti-VEGF therapy with bevacizumab limited cardiovascular toxicity. Asian Pac J Cancer Prev. 2014;15(24): 10769-10772.

37. Garcia-Donas J, Esteban E, Leandro-García LJ, et al. Single nucleotide polymorphism associations with response and toxic effects in patients with advanced renal-cell carcinoma treated with first-line sunitinib: a multicentre, observational, prospective study. Lancet Oncol. 2011;12(12):1143-1150.

38. Aronow WS, Fleg JL, Pepine CJ, et al. ACCF/AHA 2011 expert consensus document on hypertension in the elderly: a report of the American College of Cardiology Foundation Task Force on Clinical Expert Consensus Documents. Circulation. 2011;123(21):2434-2506.
39. Mancia G, Laurent S, Agabiti-Rosei E et al. Reappraisal of European guidelines on hypertension management: a European Society of Hypertension Task Force document. Journal of hypertension. 2009;27(11):2121-2158.

40. Izzedine H, Ederhy S, Goldwasser F, et al. Management of hypertension in angiogenesis inhibitor-treated patients. Ann Oncol. 2009; 20(5):807-815.

41. Sato $Y$, Sonoda $H$. The vasohibin family: a negative regulatory system of angiogenesis genetically programmed in endothelial cells. Arterioscler Thromb Vasc Biol. 2007;27(1):37-41.

42. Runge Sørensen C, Madsen JK, Schmidt F, Sloth E. [No evidence for renal protective effect of loop diuretics for patients having oliguria.] Ugeskr Laeger. 2012;174(43):2617-2620. Danish.

43. Jaeschke R, Gajewski P, Brozek J. Cardiovascular thrombotic events in controlled, clinical trials of rofecoxib. Circulation. 2002;106(5):e18.

44. Dhurandhar EJ, Kaiser KA, Dawson JA, Alcorn AS, Keating KD, Allison DB. Predicting adult weight change in the real world: a systematic review and meta-analysis accounting for compensatory changes in energy intake or expenditure. Int J Obes (Lond). Epub 2014 Oct 17.

45. Sedgwick P. Meta-analyses: what is heterogeneity? BMJ. 2015;350: h1435.

46. Zhang Z, Xu X, Ni H. Small studies may overestimate the effect sizes in critical care meta-analyses: a meta-epidemiological study. Crit Care. 2013;17(1):R2 


\section{Supplementary material}

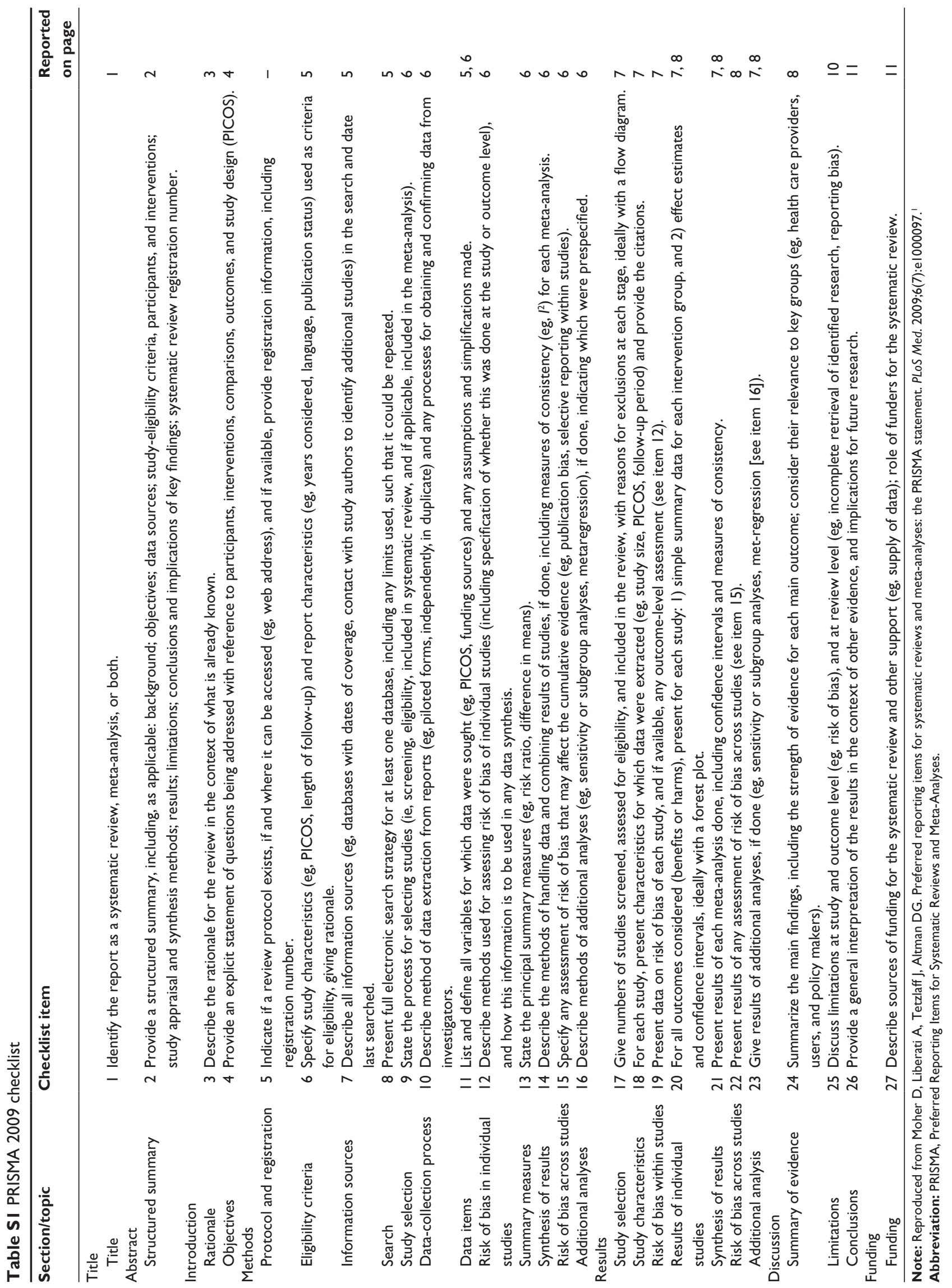




\section{Reference}

1. Moher D, Liberati A, Tetzlaff J, Altman DG. Preferred reporting items for systematic reviews and meta-analyses: the PRISMA statement. PLoS Med. 2009;6(7):e1000097.

\section{Publish your work in this journal}

Drug Design, Development and Therapy is an international, peerreviewed open-access journal that spans the spectrum of drug design and development through to clinical applications. Clinical outcomes, patient safety, and programs for the development and effective, safe, and sustained use of medicines are a feature of the journal, which

has also been accepted for indexing on PubMed Central. The manuscript management system is completely online and includes a very quick and fair peer-review system, which is all easy to use. Visit http://www.dovepress.com/testimonials.php to read real quotes from published authors.

Submit your manuscript here: http://www.dovepress.com/drug-design-development-and-therapy-journal 